Larson et al.

Globalization of Risk Perception of Vaccines((Author: please confirm/amend))

\title{
The Globalization of Risk and Risk Perception
}

\author{
Why We Need a New Model of Risk Communication for Vaccines
}

Heidi Larson, Pauline Brocard Paterson and Ngozi Erondu

Department of Infectious Disease Epidemiology, London School of Hygiene and Tropical

Medicine, Keppel Street,London-WC1E 7HT, UK

Correspondence: Dr Heidi Larson,((Author: please confirm Dr is your correct title))

Department of Infectious Disease Epidemiology, London School of Hygiene and Tropical Medicine, Keppel Street, London WC1E 7HT, UK.

E-mail: Heidi.larson@ 1shtm.ac.uk((Author: please confirm that you are happy for us to publish your e-mail address))

Abstract

Risk communication and vaccines is complex and the nature of risk perception is changing, with perceptions converging, evolving, and having impacts well beyond specific geographic localities and points in time, especially when amplified through the i̇nternet and other modes of global communication.

This article examines the globalization of risk perceptions and their impacts, including the example of measles and the globalization of measles, mumps and rubella (MMR) vaccine risk perceptions, and calls for a new, more holistic model of risk assessment, risk communication and risk mitigation, embedded in an ongoing process of risk management for vaccines and immunization programmes. It envisions risk communications as an ongoing process that includes trust-building strategies hand-in-hand with operational and policy strategies needed to mitigate and manage vaccine-related risks, as well as perceptions of risk.

Keywords: Human-papillomavirus-vaccine; Measles-mumps-and-rubella-virus-vaccine; Risk-management; Vaccines.((Author: these keywords are for our internal use only and can be ignored))

\section{$<$ ARTICLE.PART>}

((Author: If you add a reference to this article, please add it to the end of your current reference list - our system will automatically renumber the reference citations so that they are sequential prior to page proofs being created)) 


\section{Introduction}

The need for effective vaccine risk communication is well-_established ${ }_{\bar{F}},{ }^{[1-4]}$ and is becoming increasingly important in light of the growing global diversity of vaccines and vaccine schedules, compounded by a more complex communication environment and growing pockets of vaccine hesitancy around the world.

We live in a time of short attention spans and eagerness for 'quick fix' solutions, without often thinking of the longer-term implications of our actions. Parents are making decisions, sometimes driven by short-term vaccine scares, for children who have no choice or voice and who may become seriously ill with easily preventable diseases later in life because of not being vaccinated as a child.

It is difficult to talk about risk communication outside of the context of a broader continuum of ongoing risk management, which includes risk assessment and understanding of risk perceptions, which can vary widely depending on historic experiences as well as socioeconomic, cultural ${ }_{5}^{[5-7]}$ and political contexts. ${ }^{[8,9]}$ Comprehensive risk prevention and management plans are needed which include strong risk communication components, and which consider risks to individuals, risks to-society; and risks to-immunization programmes.

While there are systems in place for vaccine safety vigilance around the world, albeit some more robust than others, there are few systems in place which that monitor not only specific vaccine safety concerns, but also other public concerns about vaccines and immunization programmes which that can pose equal risks to vaccination programmes if not heard and addressed.

\subsection{What Do We Mean by “" "Risk'”?}

In 2002, the World Health OrganizationWHO's annual World Health Report chose the theme of "reducing risks, promoting healthy life" and defined risk as "a probability of an adverse outcome, or a factor that raises this probability". The 2002 report emphasizes the importance of recognizing the socio-cultural and economic factors that affect people's risk perceptions as well as the importance of considering these factors when designing risk management policies. ${ }^{[10]}$

Some of the best work on risk perception and risk communication has evolved in the environmental sciences in response to citizen debates around nuclear energy plants and other technologies that had high perceived risks among some citizen groups. Peter Sandman, renowned risk communication expert, developed a now classic formula for risk communication: Risk $=$ Hazard + Outrage, recognizing that there are various factors that influence outrage as well as perception of hazard. ${ }^{[11,12]}$ 
In the vaccine field, the focus on risk communication is often specific to vaccine safety and on communicating the benefits of vaccines as well as being transparent about the potential risks of an adverse event following immunization (AEFI)((Author: abbreviation not used again. Ok to delete?)). More attention is needed on communicating the potential risks to societies as well as reputational risks to immunization programmes of unmanaged risk perceptions and vaccine anxieties left unaddressed.

Furthermore, it is important to take into account the multiple dimensions of risk. Risk expert Paul Slovic talks about different aspects of risk. He characterizes three types of risk: "Risk as feelings refers to our fast, instinctive, and intuitive feelings to danger. Risk as analysis brings logic, reason, and scientific deliberation to bear on hazard management_..._and the third reality, risk as politics."[13]

In addressing risk communication around vaccines, "-risk as analysis"- is often the primary mode of risk wich-that is considered, with only recently emerging attention paid to the equally important domains of "“risk as feelings" " and "-risk as politics"”. The emerging shift in the public health community to increasingly acknowledge the broader realms of "-risk as feelings'"and "-as politics"” is largely in response to having been faced with an epidemic of crises in public confidence in vaccines. These include persisting concerns around the measles, mumps; and rubella (MMR) vaccine despite ample evidence refuting suspected links between the MMR vaccine and autism; and outright anti-vaccination movements which that heen driven by "risk as feelings"' or "-risk as politics"”-, which have led to behavioural outcomes such as delaying or refusing vaccines. An example is the 2003-2004 state-wide boycotts of the oral polio vaccination in five states in northern Nigeria $_{2}$ which were $_{2}$ in large part, driven by politics..$^{[14,15]}$

While northern Nigeria boycotted the oral polio vaccine (OPV)-vaceine((Author: ok?)), similar fears of OPV causing sterilization were circulating in India. ${ }^{[16]}$ ButHowever, in the case of India, there were other underlying programmatic concerns which that were driving the anxieties. Even though the expressed concern was that the oral polio vaccineOPV caused sterilization (because that was what others in the community were saying), local research revealed that the real anxiety among some was that they preferred that their children were vaccinated by a woman, rather than a man, and that the vaccinator was from the local community and not from a distant area. The exercise of even engaging in dialogue was a trustbuilding gesture, and the adapting of the vaccine delivery mode to accommodate the local preferences contributed to a decrease in vaccine anxieties and increased the take-up of the 
vaccine, in a situation where more communication targeted to the community about the safety of the vaccine would not have alleviated the concerns.

Without sitting down with those who are anxious about vaccines and discussing more explicitly why they are afraid of a particular vaccine and what might alleviate their fears, the appropriate risk management intervention would not have been known and "-more of the same"'communication on the benefits of the vaccine might have only aggravated popular anxieties.

In another example, the 2010 suspension of the human papillomavirus (HPV)((Author: ok?)) vaccine demonstration project in India $^{[17]}$ illustrates that there can be multiple levels of risk perception, in multiple locations, that may have their impact in a geographic location different from the source of the amplified risk perception. In the HPV vaccine project in India, different modes of vaccine delivery were being compared in two states (Gujarat and Andhra Pradesh) where there had been ample community engagement before and during the project's implementation, and acceptance levels of the vaccine in both states were high. The risk perceptions and activism that ultimately led to the suspension of the project ene-1 year before its completion came from outside the local areas where the project was being carried out, and instead were driven by a member of parliament from the Communist Party of India, coming from West Bengal, along with a women's group in Delhi, and supported by an anti-HPV vaccination group in the United States US called truthaboutguardasil.org.

Another example of spatially diverse risk perceptions were the concerns and anti-vaccination movements in the 1970 s which questioned the safety and relevance of the pertussis vaccine, ${ }^{[18]}$ and led to increases in pertussis cases in several countries, including Sweden, Japan, the UK, the Russian Federation, Ireland, Italy and Australia. The anti-vaccine sentiments included those of paediatricians and virologists who questioned the continued need for the vaccine - relative to its risks - despite the fact that its use had significantly reduced the incidence of pertussis following its successful introduction in the 1950s.

Two decades after the multi-country pertussis vaccine concerns and the consequent disease outbreaks, a new crisis of confidence emerged - and globalized - around the MMR vaccine.

\subsection{The Globalization of Risk Perception: The Example of Measles}

The year 2013 will mark 50 years since the first measles vaccine was licenesed. Despite the widespread use and demonstrated efficacy of the measles vaccine since its first 1963 licensure, 
there were 34250 confirmed cases of measles across the WHO European Rregion ${ }^{1}$ alone in 2011. ${ }^{[19]}$

Measles outbreaks due to under-vaccination also occurred in Ukraine, Russia and the UK in 2012, and there were a high number of cases in the US, Canada, Australia, New Zealand, Kenya, Somalia, India and Mozambique. ${ }^{[20]}$ The reasons are varied; but in a number of these countries infrastructure is not the primary barrier to vaccine coverage. Instead, a combination of perceptions of low risk around measles disease and perceptions of the vaccine being high risk has converged to create gaps in vaccine coverage, gaps in herd immunity and consequent disease outbreaks. In some cases, adverse events have given genuine cause for concern, such as around the Urabe mumps strains used in some of the MMR vaccines in the 1990s and, in other cases, new research which has prompted public concerns and debate, such as around the purported links between MMR and autism- leading to what Seth Mnookin ${ }^{[52]}$ calls the 'panic virus'.

In 1992, four 4 years after the MMR vaccine was introduced in the UK, the Department of Health withdrew MMR vaccines containing the Urabe strain of the mumps virus after an association with an increased risk of aseptic meningitis was found. ${ }^{[21]}$ Canada, Japan and Brazil also suspended the same type of MMR vaccine as evidence emerged of safety risks. Although there was no initial decline in the MMR (without the Urabe strain) vaccine coverage in the UK, the episode contributed to fertile ground for public questioning. ${ }^{[22,23]}$

Acceptance of the MMR vaccine in the UK reached a high of nearly $92 \%$ for children under the age of 2 years two-in 1994-1995. ${ }^{[24]}$ ButHowever, in the decade that followed, a barrage of questions and concerns contributed to a steady 10-year decline in vaccine coverage, the lowest being at a dangerously low $79 \%$ in $2003-2004,{ }^{[25]}$ following the widely publicized claims propagated by Andrew Wakefield that there were links between the MMR vaccine, bowel disease and autism. ${ }^{[26]}$ Although the links have been widely scientifically refuted, ${ }^{[27-29]}$ and MMR vaccine coverage rates have improved, some concerns persist in the UK. Additionally, purported links between the vaccine preservative thimerosal and autism have fuelled other vaccine anxieties, ${ }^{[30-32]}$ initially in the USA, but becoming more global.

Today the UK claims an MMR coverage rate of $89.1 \%$ as the National Health Service (NHS) and the concerned public continue a more than decade-long battle to restore coverage rates to above 90\%. ButHowever, in the meanwhile, Andrew Wakefield continues to propagate his beliefs, ${ }^{[33]}$ and the MMR vaccine anxieties, along with their consequences of reduced vaccine

${ }^{1} 42$ Forty-two Mmember Ss states as defined by the World Health OrganizationWHO. 
uptake and disease outbreaks, have slowly travelled around the world, often merging with other underlying historic vaccine concerns.

Using Peter Sandman's lens of Risk = Hazard + Outrage, there is a convergence of overly high outrage about the risks of the MMR vaccine alongside perceptions of disease hazard which are lower than the real hazard which-that measles disease warrants. ${ }^{[34-37]}$ An extreme example of under-recognition of the potential serious risks of measles is a recent children's book published in Australia titled, Melanie's Marvellous Measles. As the publisher describes the book on its website:

-"This book takes children aged 4-10 years on a journey of discovering about the ineffectiveness of vaccinations, while teaching them to embrace childhood disease, heal if they get a disease, and build their immune systems naturally.",[38]

Globally, the immunization community is facing what a gathering of immunization experts has termed "A Crisis of Public Confidence in Vaccines." ${ }^{[39]}$ Others have voiced similar concerns. ${ }^{[40]}$ The reasons for this crisis span from safety concerns to philosophical and religious beliefs, ${ }^{[41-44]}$ and from distrust in governments to theories of political and business motives behind the provision of vaccines rather than a sincere intention to prevent disease, such as around the H1N1 vaccination.

In the 2009 report to the WHO's executive board on the state of global measles elimination, WHO recognized that infrastructure was not the major barrier to adequate measles vaccine coverage in Europe, and concluded that, "Pphilosophical and religious beliefs as well as misplaced concerns about vaccine safety are the principle barriers to achieving measles elimination. ${ }^{[[45]}$ Country-specific reports throughout the region ${ }_{\overline{5}}^{[46,47]}$ confirm this.

Religious and philosophical beliefs and misplaced - as well as some legitimate - concerns which are affecting vaccine acceptance are not unique to Europe. In 2011, the United States US saw the highest number of measles cases in 15 years. Of the 222 reported cases, 141 were unvaccinated even though they were eligible to receive the MMR vaccination. Among the 66 unvaccinated cases between 16 months and 19 years oldof age, CDC $\underline{\text { the Centers for Disease }}$ Control and Prevention reported that $76 \%$ were not vaccinated because of "-religious, philosophical or personal objections'”- And a outside the US through travel abroad or through foreign visitors, $46 \%$ were from measles disease contracted in the WHO European Rregion. ${ }^{[48]}$

In other parts of the world, the WHO reports similar concerns in their Aannual Rreport on measles progress in the WHO African Rregion, 2009-2010, where they point to religious reasons behind non-vaccination in Botswana, Malawi, South Africa and Zimbabwe. ${ }^{[46]}$ 
Concurrent with these local religious and philosophical reasons for non-vaccination is an increased global spread of safety concerns. In many cases, multiple types of concerns converge or are corroborated - to substantiate a particular anxiety about a vaccine. South Africa, for instance, is seeing the emergence of anti-vaccination groups, ${ }^{[49]}$ including those spreading concerns about links between the MMR vaccine and autism, drawing largely from US and UK anti-vaccination websites, some of which are also driven by "-risk as feelings"-" and "“risk as politics"'-".

\subsection{Future Directions: A New Model for Vaccine Risk Communication}

Vaccine risk communication is complex as it needs to address not only communicating both the risks and benefits of vaccines at the individual level, but also at the societal level, including communicating the risks of not vaccinating. It also implies ongoing attentiveness to understanding perceptions of risks, as well as mitigating potential risks by ensuring that vaccine delivery strategies take into account socio-cultural and political realities which can disrupt programmes if they are not planned, and timed, well. Trust-building in immunization programmes needs to be an ongoing task. ${ }^{[51]}$

We stress the importance of managing perceptions of vaccine-related risks and adverse events as being as important as managing scientifically assessed risks and adverse events following immunization. Vaccine-related adverse events, as well as perceived, but coincidental, events, can both influence a population's willingness to accept a vaccine. ${ }^{[50]}$ We also urge the expansion of risk communication to move beyond a focus on an individual vaccine and its potential risk to the individual, to a broader consideration of risks to society and to the functioning of any immunization programme, including the potential reputational risks of inadequate risk preparedness or badly managed adverse events. Finally, we urge a consideration of more farreaching impacts of unmanaged risk perceptions and risk events well beyond specific geographical areas, especially when amplified through the i- Internet and other modes of global communication.

To capture this expanded framing of vaccine risk communication, below isfigure 1 shows a proposed, integrated model where risk communication is embedded in an overall process of risk management from risk assessment to inform risk communication with the objective to achieve risk mitigation for vaccines and immunization programmes $\therefore$ :

Fig. 1 


\subsection{Conclusions}

The nature of risk perception is changing, with multiple translocal and transnational perceptions converging, evolving, and having spatial and temporal impacts well beyond specific geographic localities and moments of hesitancy or crises in vaccine confidence.

This paper article introduces a new, more holistic model of risk assessment, risk communication and risk mitigation for vaccines and immunization programmes,$\overline{-}$ In this model, where-risk communication is embedded in an ongoing process that includes communication and trust-building strategies hand-in-hand with operational and policy strategies needed to reduce risks, as well as perceptions of risk, which can lead to vaccine hesitancy or refusals. Trustbuilding in immunization programmes needs to be an ongoing task. ${ }^{[51]}$

In order to inform this new approach to risk communication, more research is needed on both proximal and distal determinants of vaccine hesitancy and refusals. Furthermore, research needs $\underline{\text { to move beyond surveys and point-in-time research to include longitudinal studies capturing }}$ influences on vaccine hesitancy and trust in vaccines over time. In particular, research is needed which better understands and isolates the "tipping point" influences that move vaccine hesitant individuals or groups to becoming vaccine refusers or, alternatively, vaccine advocates.

We live in a time of short attention spans and eagerness for " "quick fix" solutions, without often thinking of the longer-term implications of our actions. Parents are making decisions, sometimes driven by short-term vaccine scares, for children who have no choice or voice and who may become more seriously ill with easily preventable diseases later in life because of not being vaccinated as a child ((Author: change ok?)), because of not being vaccinated as a child. The recent surge of measles outbreaks are largely among those who have not been vaccinated, either becattse they are too young to be vaceinated, or because they were not vaccinated at the recommended age in childhood because of what Seth Mnookin ${ }^{[52]}$ calls the " "panic virus"".

((Author: please remove references from this section and add to the main text. Please add a comment or two on avenues for future research.

\section{$</$ ARTICLE.PART >}

Acknowledgements

No sources of funding were used to prepare this manuscript. Heidi Larson has received grants from the Bill and \& Melinda Gates Foundation, and an honorarium from Pfizer for lecturing (a one-off). Pauline Brocard Paterson has receivedworked as a Research Fellow with Heidi Larson Commented [H1]: The Foundation insists on "\&" instead of "and" on a grant from the Bill and\& Melinda Gates Foundation. Ngozi Erondu has no conflicts of interest to declare. 
((Author: please confirm these statements are correct and complete, or amend.))

\section{References}

[1] National Research Council. Improving risk communication. Washington, DC: National Academy Press, 1989

[2] Fischhoff B. Risk perception and communication unplugged: twenty years of progress. Risk Analysis 1995; 15 (2): 137-45

[3] Slovic P. Perception of risk. Science 1987; 236: 280-5

[4] General recommendations on immunization: recommendations of the Advisory Committee on Immunization Practices (ACIP). Preventing and managing adverse reactions: benefit and risk communication. General recommendations on immmnization: recommendations of the Advisory Committee on Immmunization Practices (ACIP).MMWR Recomm Rep 2011; 60 (2): 1-64

[5] Leach M, Fairhead J. Vaccine anxieties: global science, child health and society. London: Earthscan, 2007. (Seience in Society Series)

[6] Wildavsky A, Dake K. Theories of risk perception: who fears what and why? Daedalus 1990; 119 (4): 41-60

[7] Kaler A. Health interventions and the persistence of rumour: the circulation of sterility stories in African public health campaigns. Soc Sci \&-Medicine 2009; 68: 1711-9

[8] Evans G, Bostrom A, Johnston RB, et al., editors. Risk communication and vaccination. Washington, DC: Institute of Medicine, National Academy Press, 1997

[9] Pidgeon N, Kasperson R, Slovic P. The social amplification of risk. London: Cambridge University Press, 2003

[10] WHO. World health report: reducing risks, increasing healthy lives.; Geneva: WHO, 2002

[11] Sandman PM. Responding to community outrage: strategies for effective risk communication. Fairfax, (VA): American Industrial Hygiene Association ${ }_{2} ; 1993$. (Copyright transferred to the author, Peter M. Sandman, in 2012)

[12] Sandman PM. Hazard versus outrage in the public perception of risk. In: Covello VT, McCallum DB, Pavlova MT, editors. Effective risk communication: the role and responsibility of government and nongovernment organizations. New York- (NY): Plenum Press, 1989: 45-9 [13] Slovic P, Finucane ML, Peters E, et al. Risk as analysis and risk as feelings: some thoughts about affect, reason, risk, and rationality. Risk Analysis 2004; 24 (2): 311-22

[14] Yahya M. Polio vaccines__- difficult to swallow: the story of a controversy in Northern Nigeria. IDS Wworking Ppaper 261 [Internetonline]. Z006 [cited 2012 April 17].Available from URL: http://www.ids.ac.uk/files/Wp261.pdf $₫$ Accessed 2012 Apr 171

[15] Jegede AS. What led to the Nigerian boycott of the polio vaccination campaign? PLOS Medicine 2007 Mar; 4 (3): e73

[16] Obregon R, Waisbord S. The complexity of social mobilization in health communication: top-down and bottom-up experiences in polio eradication. J Health Commun 2010; 15: 25-47

[17] Larson H, Brocard P, Garnett G. The India HPV vaccine suspension. Lancet 2010; 376 (9741): 572-3

[18] Gangarosa EJ, Galazka AM, Wolde CR, et al. Impact of anti-vaccination movements on pertussis control: the untold story. Lancet 1998; 351: 356-61

[19] WHO. EPI brief (February 2012). Geneva: WHO, 2012 ((Author: is this document available online? If so, please provide website address details)) 
[20] WHO-/UNICEF. Joint statement: global plan for reducing measles mortality 2006-2010; 2006 Jan [eited 2012 March 27]. 4p. [online]. Available from URL:

http://www.who.int/immunization_delivery/adc/measles/Measles\%20Global\%20Plan_Eng.pdf [Accessed 2012 Mar 27]

[21] Elliman D, Bedford H. MMR: where are we now? Arch Dis Child 2006; 92 (12): 1055-7

[22] Larson H, Heymann D. Public health response to influenza A (H1N1) as an opportunity to build public trust. JAMA 2010; 303 (3): 271-2

[23] Betraying the public over nvCJD risk [editorial]. Lancet 1996; 348 (9041): 1529

[24] UK Department of Health. NHS immunisation statistics, England: 1997-1998-T (table 2)Completed primary courses: percentage of children immunised by their second birthday, 1988 89 to 1997 98. [cited 2012 March 12][online]. Available from URL:

http://www.dh.gov.uk/en/Publicationsandstatistics/Statistics/StatisticalWorkAreas/Statisticalheal thcare/DH_4016221 [Accessed 2012 Mar 12]

[25] UK Department of Health. NHS immunisation statistics, England: 2010-11. Immunisations received by first and second birthday. Measles, mumps and ruebella; 2011 Sept 21 [cited 2012 March 12]. [onlinel. Available from URL:

http://www.ic.nhs.uk/webfiles/publications/003_Health_Lifestyles/Immunisation\%20Stats\%202 010-11/Immunisations_Bulletin_2010_11_v1_23.pdf[Accessed 2012 Mar 12]((Author: please note change in website address and confirm this is correct))

http://www.ic.nhs.uk/statistics-and-data-collections/health-and-

lifestyles/immunisation/nhs-immunisation-statistics-england-2010-11

[26] Offit P, Coffin S. Communicating science to the public: MMR vaccine and autism. Vaccine 2003; 22 (1): 1-6

[27] Madsen KM, Hviid A, Vestergaard M, et al. A population-based study of measles, mumps, and rubella vaccination and autism. N Engl J Med 2002; 347: 1477-82

[28] Wilson K, Mills E, Ross C, et al. Association of autistic spectrum disorder and the measles, mumps, and rubella vaccine: a systematic review of current epidemiological evidence. Arch Pediatr Adolesc Med 2003; 157 (7): 628-34

[29] Honda H, Shimizu Y, Rutter M. No effect of MMR withdrawal on the incidence of autism: a total population study. J Child Psychol Psychiatr 2005; 46 (6): 572-9

[30] Parker SP, Schwartz B, Todd J, et al. Thimerosal-containing vaccines and autistic spectrum disorder: a critical review of published original data. Pediatrics 2004; 114 (3): 793 -

804

[31] Katz S. Has the measles-mumps-rubella vaccine been fully exonerated? Pediatrics 2006;

118 (4): 1744-5-(doi: 10.1542/peds.2006-2252)

[32] Kirkland A. Credibility battles in the autism litigation. Soc Stud Sci 2012; 42 (2): 237-61

[33] Wakefield AJ. Callous disregard. A: autism and vaccines - the truth behind a tragedy [online]. 2010. [cited 2012 April 24]. Available from URL: http://www.callous-disregard.com/ [Accessed 2012 Apr 24]

[34] Pearce A, Law C, Elliman D, et al., Millennium Cohort Study Child Health Group. Factors associated with uptake of measles, mumps, and rubella vaccine (MMR) and use of single antigen vaccines in a contemporary UK cohort: prospective cohort study. BMJ 2008; 226 (7647): 754-7 [35] Casiday R, Cresswell T, Wilson D, et al. A survey of UK parental attitudes to the MMR vaccine and trust in medical authority. Vaccine 2006; 24 (2): 177-84

[36] Casiday R. Children's health and the social theory of risk: insights from the British measles, mumps and rubella (MMR) controversy. Soc Sci Med 2007; 65 (5): 1059-70 
[37] Burgess DC, Burgess MA, Leask J. The MMR vaccination and autism controversy in United Kingdom 1998-2005: inevitable community outrage or a failure of risk communication? Vaccine 2006; 24 (18): 3921-8

[38] Messenger S. Melanie's marvellous measles. Australia: Nature Matters, 2010((Author: please specify city of publication. It is a book))

[39] Black S, Rappuoli R. A crisis of public confidence in vaccines. Sci Transl Med 2010; 2

(61): 61 mr1((Author: please confirm page range is correct. YES))

[40] Shetty P. Experts concerned about vaccination backlash. Lancet 2010 Mar 20; 375 (9719): 970-1

[41] Poethko-Müller C, Ellert U, Kuhnert R, et al. Vaccination coverage against measles in German-born and foreign-born children and identification of unvaccinated subgroups in Germany. Vaccine 2009 Apr 28; 27 (19): 2563-9

[42] CDC. Measles:_-United States, January-_May 20, 2011. MMWR 2011; 60 (20): 666-8 [online]. Morbidity and Mortality Weekly Report [internet].2011 May 27 [cited 2012 Mareh 22]; 60(20);666 668. Available from URL:

http://www.cdc.gov/mmwr/preview/mmwrhtml/mm6020a7.htm?s_cid=mm6020a7_w [Accessed 2012 Mar 22]

[43] WHO. Weekly epidemiological record. Progress in global measles control, 2000-2010 [onlinefnternet]. 2012 February 3 [eited 2012 March 27];87(5): 45 52. Available from URL: http://www.who.int/wer/2012/wer8705.pdf [Accessed 2012 Mar 27]

[44] WHO. Weekly epidemiological record. Measles outbreaks and progress towards meeting measles pre-elimination goals: WHO African region, 2009-2010 [onlineInternet]. 2011 April 1 [eited 2012 March 27] 86(14):129 140.Available from URL:

http://www.who.int/wer/2011/wer8614.pdf」Accessed 2012 Mar 27]

[45] WHO. Global elimination of measles: report by the Secretariat-. WHO Executive Board, 125th Session; 2009 April 16. Report No::EB125/4 [online]. Available from URL:

http://apps.who.int/gb/ebwha/pdf_files/EB125/B125_4-en.pdf [Accessed 2012 Aug 28$]$

[46] Data from the representative German Health Interview and Examination Survey for Children and Adolescents. Article referencing: Poethko-Müller C, Ellert U, Kuhnert R,

Newhatser H, Schlatd M, Schenk L. (2009)et al. Vaccination coverage against measles in German-born and foreign-born children and identification of unvaccinated subgroups in Germany. Vaccine 2009 Apr 28; 27 (19): 2563-9. Epub 2009 Feb 12

[47] Woonink F. When parents refuse vaccination. National Institute for Public Health and the Environment, the Netherlands, 2009 [online]. Available from URL: http://

www.ggdmn.nl/scripts/download.asp?ID=4616 [Accessed 2012 Apr 21]((Author: I am unable to access this website. Please confirm website address is correct))

[48] CDC. Measles: United States, 2011. Morbidity and Mortality Weekly Report (MMWR). April 20,2012; ‘61_(15):; 253-257_online]. Available from URL:

http://www.cdc.gov/mmwr/preview/mmwrhtml/mm6115a1.htm\#tab [Accesseds on $2012 \mathrm{Apr}$ 21]

[49] Burnett RJ, Larson HJ, Moloi MH, et al. Addressing public questioning and concerns about vaccination in South Africa: a guide for healthcare workers. Vaccine. 2012 [In press $\exists(($ Author: has this reference been published yet? If so, please update the citation))

[50] Larson H, Cooper LZ, Eskola J, et al. Addressing the vaccine confidence gap. Lancet 2011; 378 (9790): 526-35

[51] Waisbord S, Larson H. Why invest in communication for immunization? Evidence and lessons learned. A joint publication of the Health Communication Partnership, Johns Hopkins Bloomberg School of Public Health (Baltimore) and UNICEF (New York) [Internetonline]; 2005 [cited 2012 Mar 27]. Available from URL: 
http://www.globalhealthcommunication.org/tool_docs/21/why_invest_in_communication_for_i mmunization.pdf [Accessed 2012 Mar 27]

[52] Mnookin S. The panic virus. New York: Simon and Shuster, 2011

Fig. 1. Risk Ecommunication re-framed as a component of a risk management process((Author:

Please confirm whether the last bullet point in the first frame ('Risk Assessment') should read "Assessment of external risks to vaccine delivery and the immunization programme (coinciding events, political scanning, historical events that could influence trust)", as per the original draft?)). 